\title{
UFFICERS PAST AND PRESENT
}

\section{PRESIDENTS}

J. H. VAN AMringe, 1888-1890

Thomas S. FISKE, 1902-1904

EMORY MCClintock, 1890-1894

W. F. OSGOOD, 1904-1906

G. W. HILL, 1894-1896

H. S. WhITE, 1906-1908

Simon Newcomb, 1896-1898

Maxime Bôcher, 1908-1910

R. S. WOODWARD, 1898-1900

H. B. Fine, 1910-1912

ELIAKIM H. MOORE, 1900-1902

E. B. VAN Vleck, 1912-

\section{VICE-PRESIDENTS}

Emory McClintock, 1889-1890 James Pierpont, 1904-1905

J. K. Rees, 1890-1891 Charlotte A. Scott, 1905-1906

Henry B. Fine, 1891-1893 Irving Stringham, 1905-1906

G. W. HILL, 1893-1894 HeinRICH MasChKe, 1906-1907

H. A. Newton, $1894-1896 \quad$ P. F. Sмiтн, $1906-1907$

R. S. WOODWARD, 1896-1898 JAMES HARKNESS, 1907-1908

ELIAKIM H. MOORE, 1897-1900 G. A. MiLLER, 1907-1908

Thomas S. FIske, 1898-1901 Edward Kasner, 1908-1909

Henry S. White, 1900-1901 $\quad$ E. B. Van Vleck, 1908-1909

MAXime Bôcher, 1901-1902 $\quad$ L. E. Dickson, 1909-1910

Frank Morlex, 1901-1902 J. I. Hutchinson, 1909-1910

W. F. OSGOOD, 1902-1903 G. A. BLISS, 1919-1911

ALEXANDER Ziwet, 1902-1903 $\quad$ W. E. Story, 1910-1911

OSKar BolZA, 1903-1904 H. F. BLICHFELdT, 1911-1912

J. M. VAN Vleck, 1903-1904 Henry TABer, 1911-1912

E. W. Brown, 1904-1905 M. W. HASKELL, 1912-

B. O. Peirce, 1912- 


\section{OFFICERS PAST AND PRESENT}

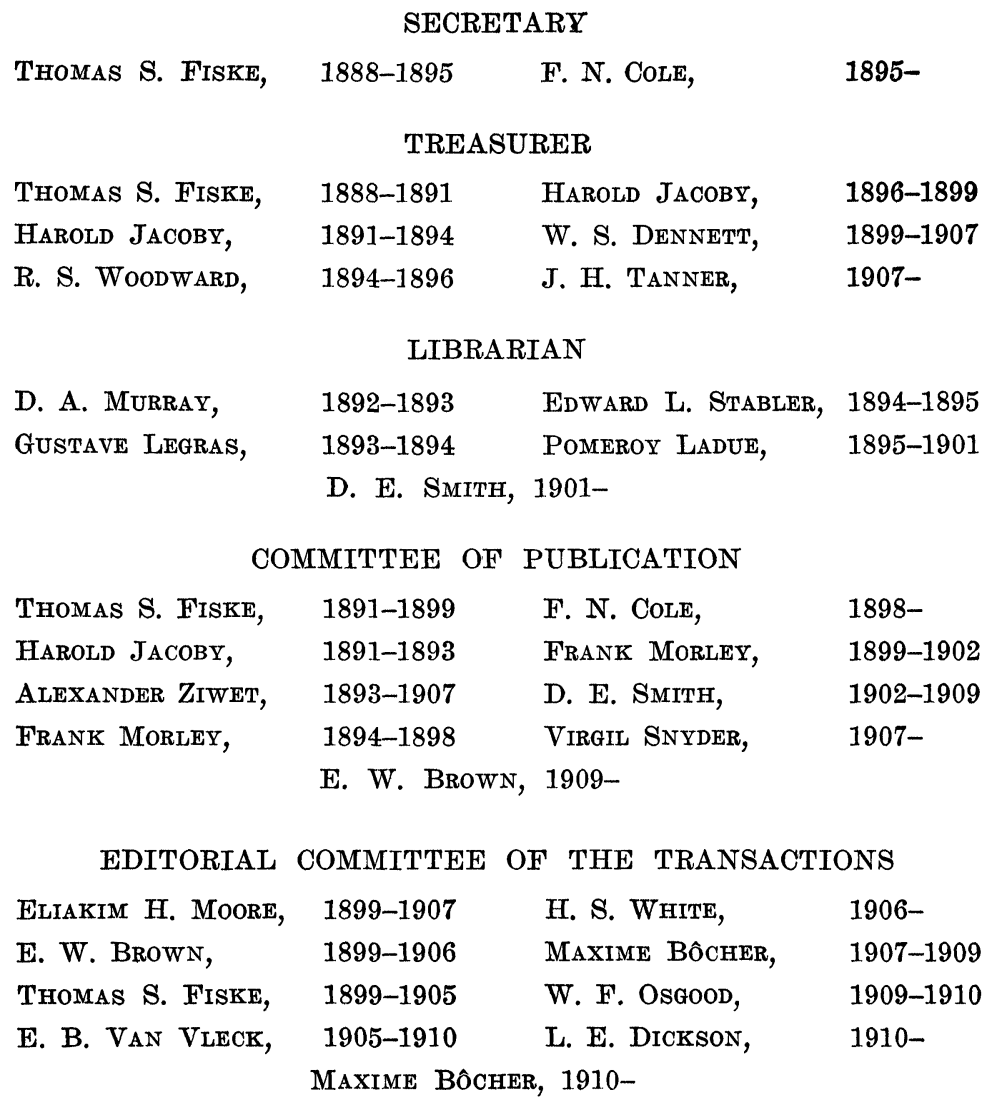

